\title{
Verification of Thermal Models of Internally Cooled Gas Turbine Blades
}

\author{
Igor Shevchenko, Nikolay Rogalev, Andrey Rogalev (iD), \\ Andrey Vegera, and Nikolay Bychkov
}

National Research University Moscow Power Engineering Institute, 14 Krasnokazarmennaya Street, Moscow 111250, Russia

Correspondence should be addressed to Andrey Rogalev; r-andrey2007@yandex.ru

Received 23 November 2017; Accepted 1 March 2018; Published 23 April 2018

Academic Editor: Lei Tan

Copyright (c) 2018 Igor Shevchenko et al. This is an open access article distributed under the Creative Commons Attribution License, which permits unrestricted use, distribution, and reproduction in any medium, provided the original work is properly cited.

\begin{abstract}
Numerical simulation of temperature field of cooled turbine blades is a required element of gas turbine engine design process. The verification is usually performed on the basis of results of test of full-size blade prototype on a gas-dynamic test bench. A method of calorimetric measurement in a molten metal thermostat for verification of a thermal model of cooled blade is proposed in this paper. The method allows obtaining local values of heat flux in each point of blade surface within a single experiment. The error of determination of local heat transfer coefficients using this method does not exceed $8 \%$ for blades with radial channels. An important feature of the method is that the heat load remains unchanged during the experiment and the blade outer surface temperature equals zinc melting point. The verification of thermal-hydraulic model of high-pressure turbine blade with cooling allowing asymmetrical heat removal from pressure and suction sides was carried out using the developed method. An analysis of heat transfer coefficients confirmed the high level of heat transfer in the leading edge, whose value is comparable with jet impingement heat transfer. The maximum of the heat transfer coefficients is shifted from the critical point of the leading edge to the pressure side.
\end{abstract}

\section{Introduction}

A gas turbine engine service life is mainly determined by lifespan of high-pressure turbine blades [1]. Creation of blade with effective cooling system is a complicated and labourintensive process. It includes selection and design of cooling loop as well as its optimisation; gas-dynamic, thermal, and strength calculations; experimental study; development of production technology; and evaluation of reliability [2-4].

Hydraulic and thermal models of cooling passages providing the determination of boundary conditions from the side of gas and cooling air are used for the purpose of calculation of thermal state of a blade during operation. The adequacy of both hydraulic and thermal models of cooling passage, which are based on the values of hydraulic resistance of paths with turbulators and on criterion dependencies for calculation of heat transfer from the passage walls to cooling air, has an influence on the accuracy of obtained results. Possible inadequacy of thermal and hydraulic models of manufactured full-size blade prototype is related to the fact that the values of hydraulic resistance and criterion equations used for the design are usually obtained from models with constant cross section of a greater size than passages of a real blade while the modelling conditions significantly differ from the full-scale ones [5-8]. There is almost no data of calculation of heat transfer in transitional parts of passage junctions, turns, and bifurcations. All of the above decrease the accuracy of calculation of temperature fields of a blade and hence the safety factor.

The modelling of blade temperature field as a result of a simultaneous solution of a single package of problems of gas and coolant flows and heat transfer with conjugation of heat exchange conditions on the walls is an up-to-date design method. However, the accuracy of obtained results (and their matching to the experimental data) depend largely on a chosen turbulence model, an approach to three-dimensional modelling and a density of grid [9-11].

Figure 1 demonstrates an example of comparison results of calculated and measured temperature values in the middle section of a studied blade, which were obtained while 


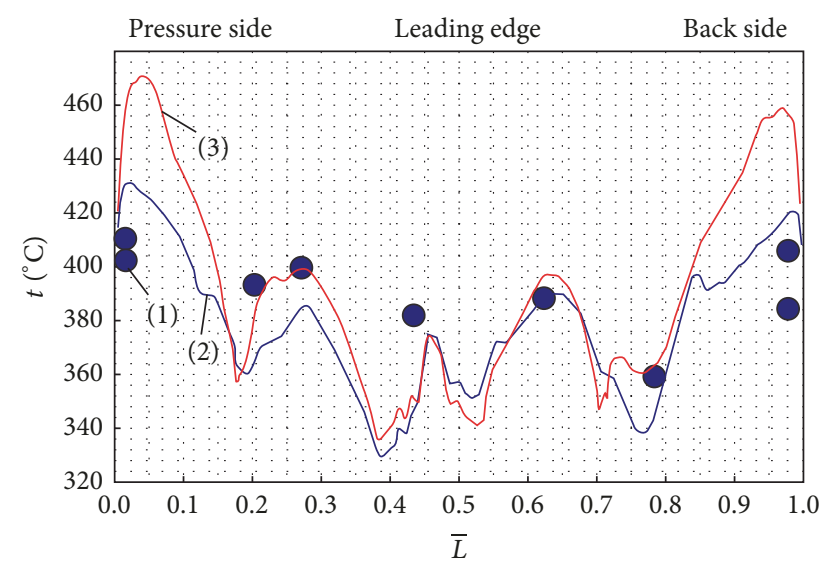

FIgURE 1: Temperature at the blade profile outline. (1) Experiment by Baranov Central Aircraft Engine Institute; (2) RKE model conjugated approach; (3) RKE model semiconjugated approach.

selecting the most accurate calculating model. In particular areas, the discrepancy is up to $40^{\circ} \mathrm{C}$ while the gas temperature upstream the blade cascade is $614^{\circ} \mathrm{C}$ [12].

Verification of thermal and hydraulic models shall be performed by testing the full-size blade prototype manufactured according to a batch process by using the lost-wax casting [13-15]. Essential discrepancies of thermal and hydraulic parameters to calculated values determined during the test require correction of design and technological documentation, modification of a mould, or even production of a new one for pressing ceramic cores that hollow the blade during the casting $[16,17]$. This results in significant additional costs and increases the time required for development of cooled blade as well as an engine as a whole.

During the process of reengineering of gas turbine hot section, a problem of recreation of thermal and hydraulic model of cooled blade for the purpose of calculation of its thermal state arises [18-20].

As for blades cooled by convection, a method of calorimetric measurement in a molten metal thermostat can help solve the problem of verification of thermal and hydraulic models of turbine blade cooling system [21].

This paper is dedicated to the development of verification method of thermal models of internally cooled gas turbine blades.

\section{Method of Calorimetric Measurement in the Molten Metal Thermostat}

Method of calorimetric measurement in the molten metal thermostat allows obtaining local values of heat flux in each point of blade surface experimentally [22]. An effect of phase transition of chemically pure metals is a physical basis of calorimetric method. The method proceeds as follows. A blade equipped with manifolds for supply and extraction of cooling air shall be submerged into the melt of pure zinc heated over its melting point. The blade shall be heated to the temperature of melt and then cooled along with it down to the equilibrium state at zinc melting point and below by

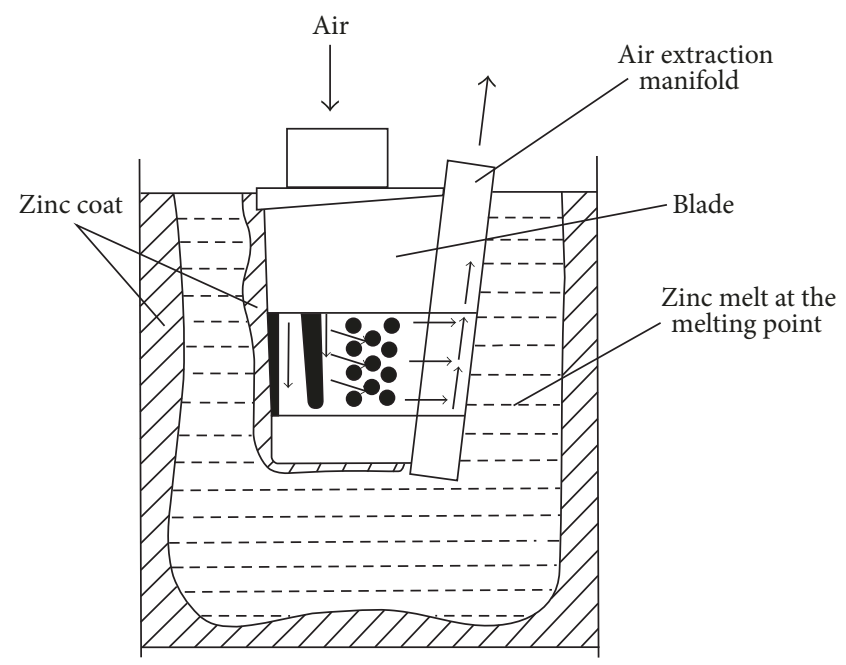

FIGURE 2: Method of calorimetric measurement in the molten metal thermostat.

the cooling air within a particular period of time. After that the blade shall be taken out of the melt (Figure 2). A metal coat formed during the process of heat transfer to the coolant passing through internal paths of the blade is crystallized on its outer surface.

Experiments in the zinc melt are usually carried out in a wide range of pressure drops $\pi_{\mathrm{a}}=P_{b} / P_{0}$, where the following parameters are measured: air consumption through the blade; incoming and outgoing air temperatures. After a series of experiments, zinc coats removed from the studied blade shall be weighted which is necessary for evaluation of the quality of experiments with respect to convergence of heat balance. The heat balance is defined as follows:

$$
G_{\mathrm{a}} \cdot C_{p} \cdot\left(T_{\mathrm{a}}^{*}-T_{\mathrm{a} \text { _out }}^{*}\right)=\frac{m_{c}}{\tau} \cdot L_{\mathrm{cr}},
$$

where $G_{\mathrm{a}}$ represents air consumption through the blade; $C_{p}$ represents heat capacity of air; $T_{a}^{*}$ represents temperature of air incoming to the blade; $T_{\mathrm{a}_{\text {_out }}}^{*}$ represents temperature of air outgoing from the blade; $m_{c}$ represents coat mass; $\tau$ represents blowing time; $L_{\text {cr }}$ represents zinc crystallization heat.

If the quality of experiment is high, then the difference in values of heat removed from the blade which were obtained by measuring of zinc coat masses and thermocouple indications should not exceed $5 \%$.

After the convergence of heat balance is checked, coats shall be marked and cut with respect to sections accepted for the study. Usually these sections match constructive cross sections of the blade. Zinc coat images enlarged by 8 to 10 times shall be obtained by scanning. The use of enlarged images allows for essential improvement of accuracy of coat thickness measurement.

The heat flux for each calculation point $q_{i}$ is defined as follows:

$$
q_{i}=\frac{\rho_{c} \cdot L_{\mathrm{cr}}}{\tau} \cdot\left[\left(\delta_{i}-\delta_{d}\right) \pm \frac{\left(\delta_{i}-\delta_{d}\right)^{2}}{2 \cdot R_{i}}\right],
$$


where $R_{i}$ represents radius of outer surface of blade; $\delta_{i}$ represents coat thickness; $\delta_{d}=0.1 \mathrm{~mm}$ represents the thickness of dragged metal layer forming while the blade is taken out of the melt; $\rho_{c}$ represents density of zinc coat; the "_" sign is used for points on the concave surface of blade.

In order to determine the values of local coefficients of heat elimination to the air, one shall know the temperature of cooling air $T_{\mathrm{a} i}^{*} . T_{\mathrm{a} i}^{*}$ values shall be calculated with respect to distribution of coolant $G_{a}$ over internal passages for test conditions in thermostat and in order to solve the heat balance equations composed for particular areas of blade surface at which the values of heat flow are determined.

The local heat transfer coefficient $h_{\mathrm{a} i}$ is defined as follows:

$$
h_{\mathrm{a} i}=\frac{q_{i}}{K_{\mathrm{sh} i}} \cdot\left(T_{\mathrm{m}}-T_{\mathrm{a} i}^{*}\right)^{-1},
$$

where $K_{\mathrm{sh} i}$ represents shape coefficient which considers the geometric difference between the blade wall and a flat thin wall; $T_{\mathrm{m}}$ represents zinc melting point.

The $\mathrm{Nu}_{\mathrm{a} i}$ and $\mathrm{Re}_{\mathrm{a} i}$ criteria shall be calculated for each point of blade surface; then they shall be approximated by the following dependencies using the least squares method:

$$
\mathrm{Nu}_{\mathrm{a} i}=A_{i} \cdot \mathrm{Re}_{\mathrm{a} i}^{m i} .
$$

The error of determination of local heat transfer coefficients $\delta h_{i}$ consists of the error of determination of heat flux and local temperature of cooling air. The relative error of determination of heat flux $\delta q_{i}$ is defined as follows:

$$
\delta q_{i}=\sqrt{\left(\delta \delta_{i}\right)^{2}+\left(\delta R_{i}\right)^{2}+\left(\delta \tau_{i}\right)^{2}+\left(\delta \rho_{i}\right)^{2}+\left(\delta L_{i}\right)^{2}},
$$

where $\delta \delta_{i}$ represents the relative error of determination of crust thickness; $\delta R_{i}$ represents the relative error of determination of curvature radius of the blade surface; $\delta \tau_{i}$ represents the relative error of blowing time determination; $\delta L_{i}$ represents the relative error of specifying the latent value of zinc crystallization; $\delta \rho_{i}$ represents the relative error of setting the heat flux.

If we assume that the values of $L_{i}$ and $\rho_{i}$ are specified with high accuracy, the relative error $\delta q_{i}$ does not exceed $\pm 5 \%$.

The error of determination of local heat transfer coefficient depends mainly on the error of determination of distribution of the air flow through the cooling channels $\delta G_{i}$ and, accordingly, on air heating and local temperature $T_{\mathrm{a} i}^{*}$. The value of $\delta G_{i}$ is determined by the complexity of the blade cooling path.

The error of determination of local heat transfer coefficients usually does not exceed $\pm 8 \%$ for blades with radial channels. An important feature of method is that all tests shall be carried out under the same external heat load and blade outer surface temperature $T_{b}$ equals zinc melting point $T_{\mathrm{m}}=$ $692.4 \mathrm{~K}$.

\section{Facility for Implementation of Method of Calorimetric Measurement in the Molten Metal Thermostat}

Despite constructive and layout solutions, a facility for testing the cooled blades in molten metal thermostat shall include the following elements (Figure 3): a system of air purification and supply; a working area for connection of object to be studied; heat measuring system consisting of a crucible with zinc melt and an oven for its heating and melting; rotary lifting mechanism ejecting the crucible from the oven, moving it to the blade, allowing putting the blade into the melt and taking it out; a system of air consumption control and measurement and recording the experimental data.

It is possible to use facilities with various layouts which basically differ from one another by degree of mechanisation of test process. These constructive differences are determined by the amount of studies, the design of tested blade, its dimensions, allocation of holes for air ejection from the blade, and experimental modes, pressure of cooling air, and the need of creation of counterpressure at the blade output.

The thermostat is the crucible with zinc melt whose cross section is oval. The crucible shall be made of highcarbon steel; its internal surface shall be coated with a thin ceramic coat that prevents the contact of the crucible surface with the melt. Dimensions of crucible and the mass of zinc shall be determined by the mass and dimensions of blade equipped with manifolds for supply and extraction of cooling air. The control panel allows manipulating the rotary lifting mechanism and cooling air supply system, in both manual and automatic modes according to a signal of timer, and recording the experimental data.

The working area connects the blade to air supply mains and is a constructive unit, which also includes the blade prototype to be studied. The working area design shall be specially developed for each series of blades and is determined by test tasks. As the working area shall not influence the thermal state of blade during the test and shall provide the given parameters of incoming cooling air, it shall comply with the following requirements. The working area shall provide the following: ability of blowing of blade with coolant while it is dipped into the zinc melt, with coolant ejection to the atmosphere and with counterpressure; the minimum heat removal from the blade by working area; absence of massive elements of connections for the purpose of decrease of thermal accumulative ability of unit.

Figure 4 demonstrates the experimental test bench. The description of the main measurement equipment is presented in Table 1.

\section{Blade Thermal Model Verification Technique}

Method of calorimetric measurement in the molten metal thermostat can be effectively used for experimental verification of thermal models of internally cooled blades.

The thermal model shall be verified by comparison of distribution of heat flux $q_{c}$ over the outer surface, which is calculated according to verified thermal model for test conditions, and distribution of heat flux $q_{z}$, which is determined from the results of experiments in the molten metal thermostat. Comparison of heat flows shall consider all parameters of thermal model that determine the thermal state of blade under the operating conditions: air consumption and temperature at the branches of equivalent hydraulic network, 


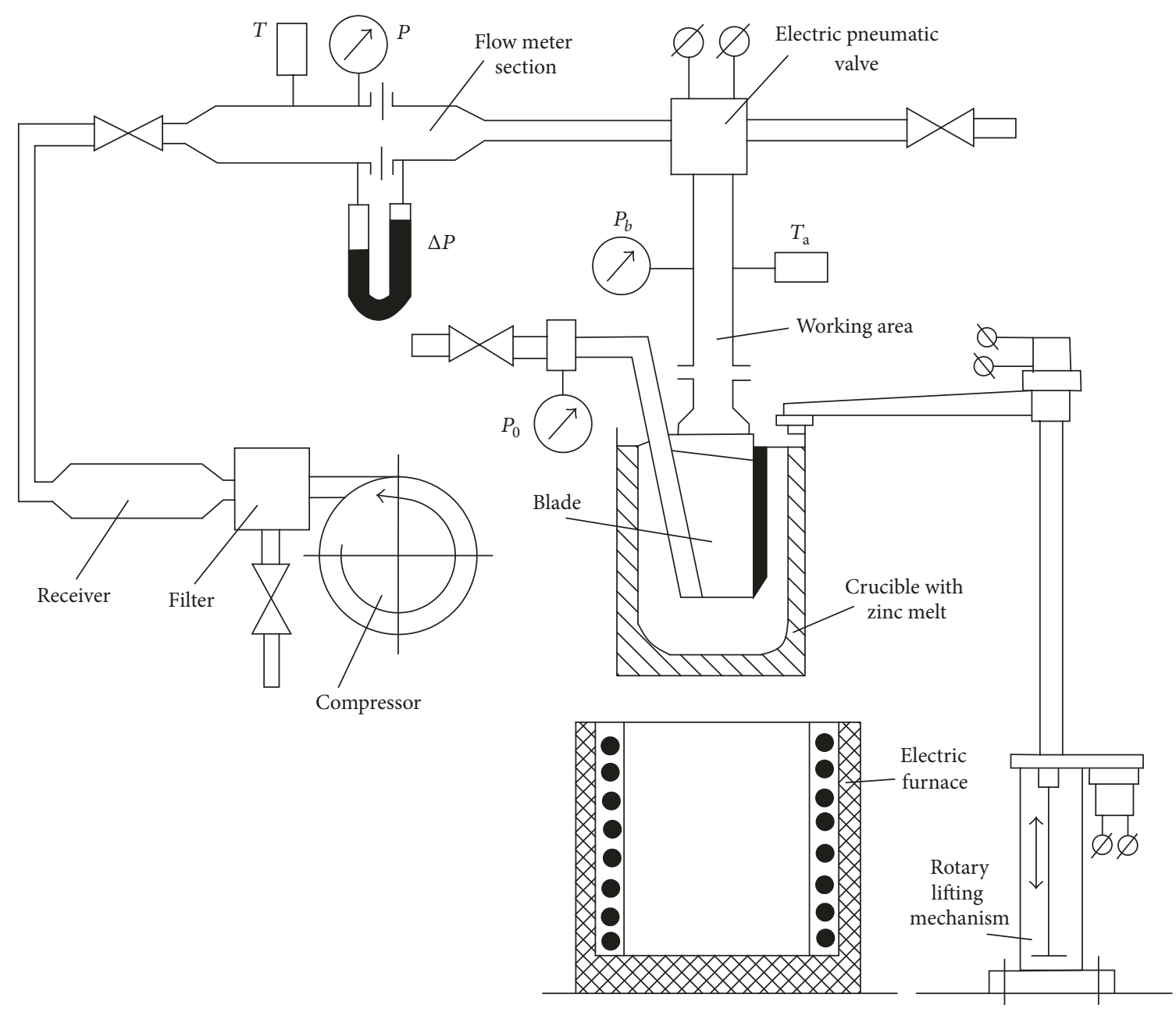

FIGURE 3: Experimental facility diagram.

TABLE 1: Accuracy of the measurement equipment. Measurement error

coefficients of heat transfer to the coolant, and blade wall shape coefficients.

While calculating the heat flow $q_{c}$ under the modelling conditions of molten metal thermostat, the following boundary condition of the first kind shall be set: the surface temperature equals zinc melting point $692.4 \mathrm{~K}$; the following boundary conditions of the third kind shall be set for the surface of cooling passages: temperature of cooling air $T_{\mathrm{a} i}^{*}$ and coefficients of heat transfer from the blade wall to cooling air $h_{\mathrm{a} i}$ obtained by using the verified hydraulic model of blade for conditions of blade test in the molten metal thermostat. The result of calculation is a two-dimensional temperature field of blade cross section and a value of heat flux in given points of outer surface.

In order to make a decision regarding the adequacy of thermal model, dependence allowing evaluation of the influence of detected differences between $q_{z}$ and $q_{c}$ on the thermal state of blade is required. For this purpose, the use of dimensionless relative temperature (the intensity of blade cooling) is advisable:

$$
\theta=\frac{T_{g}^{*}-T_{b}}{T_{g}^{*}-T_{\mathrm{a}}^{*}},
$$

where $T_{g}^{*}$ represents hot gas temperature. 


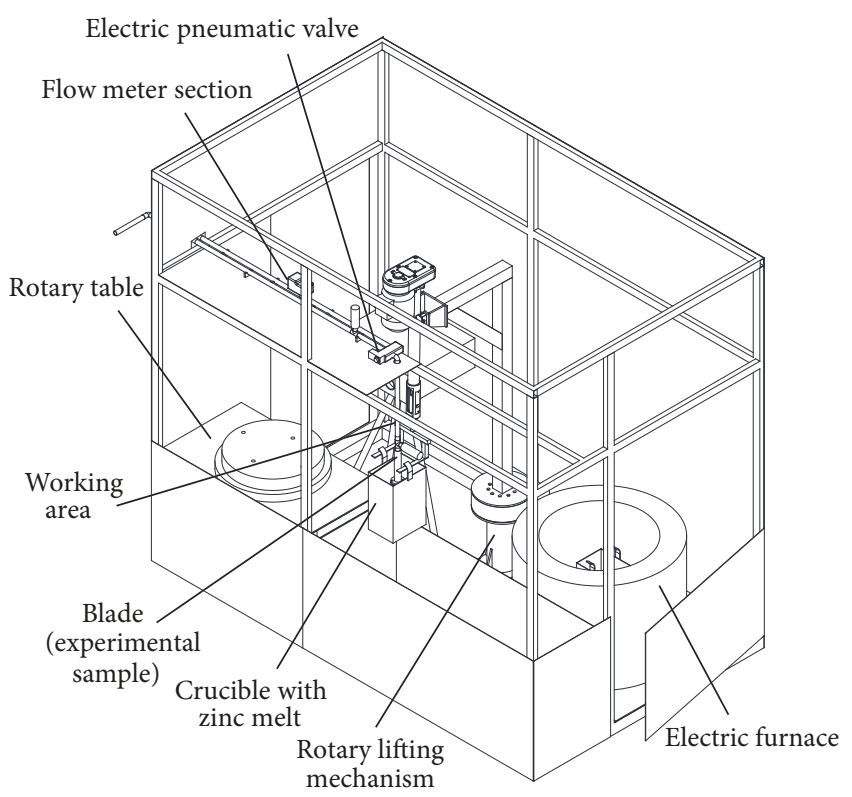

FIgURE 4: Test bench.

The following ratio is valid for each point of blade surface:

$$
\frac{1 / \theta_{b z}-1}{1 / \theta_{b c}-1}=\frac{K_{\mathrm{sh}} \cdot h_{\mathrm{ac}}}{K_{\mathrm{sh}} \cdot h_{\mathrm{a} z}}=\frac{q_{z}}{q_{c}},
$$

where $\theta_{b c}$ represents a dimensionless temperature of blade surface obtained from the results of calculation using the thermal model being verified; $\theta_{b z}$ represents a dimensionless temperature of blade surface obtained from the results of experiments in molten metal thermostat; $h_{\mathrm{ac}}$ represents a coefficient of heat transfer to cooling air applied in the thermal model being verified; $h_{\mathrm{a} z}$ represents a coefficient of heat transfer to cooling air calculated on the basis of results of experiment.

As values of experimental and calculated air consumption coincide, the ratio is valid:

$$
\frac{h_{\mathrm{ac}}}{h_{\mathrm{a} z}}=\frac{\lambda_{\mathrm{a} z}}{\lambda_{\mathrm{ac}}} \cdot\left(\frac{\mu_{\mathrm{a} z}}{\mu_{\mathrm{ac}}}\right)^{-m},
$$

where $\lambda_{\mathrm{a} z}$ represents thermal conductivity of air applied in the thermal model being verified; $\lambda_{\mathrm{ac}}$ represents thermal conductivity of air calculated on the basis of results of experiment; $\mu_{\mathrm{a} z}$ represents viscosity of air applied in the thermal model being verified; $\mu_{\mathrm{ac}}$ represents viscosity of air calculated on the basis of results of experiment; $m$ represents an exponent in the criterion equation for calculation of $h_{\mathrm{ac}}$.

The exponential dependencies are used for calculation of variations of thermal conductivity $\lambda_{\mathrm{a}}$ and viscosity of air $\mu_{\mathrm{a}}$ :

$$
\begin{aligned}
& \lambda_{\mathrm{a}}=f_{1}\left(T_{\mathrm{a}}\right)^{0.64} ; \\
& \mu_{\mathrm{a}}=f_{2}\left(T_{\mathrm{a}}\right)^{0.76} .
\end{aligned}
$$

With regard to specific values of exponent at the Reynolds number $m=0.6-0.8$, proceeding from (9), we shall obtain

$$
\frac{h_{\mathrm{a} z}}{h_{\mathrm{ac}}}=\left(\frac{T_{\mathrm{a} z}^{*}}{T_{\mathrm{ac}}^{*}}\right)^{0.64-0.76 \cdot m} .
$$

If $m=0.8$, then the difference by 1.5 times in temperatures results in the difference $q_{z} / q_{c}=1.013$. Using (7) and assuming $\theta_{b c}$ for particular area of blade as a permissible variation $\Delta \theta$, a permissive variation of $q_{c}$ and $q_{z}$ is defined as follows:

$$
\left(\frac{q_{z}}{q_{c}}\right)_{p}=\frac{1 /\left(\theta_{b c}-\Delta \theta\right)-1}{1 / \theta_{b c}-1} .
$$

If the obtained parameter value is $q_{z} / q_{c} \leq\left(q_{z} / q_{c}\right)_{p}$, then the thermal model describes the processes of internal heat exchange appropriately for this part of blade.

Comparison of $q_{z}$ and $q_{c}$ is advisable under several test modes, that is, for various pressure drops. The $q_{z} / q_{c}$ value should not practically change depending on the $P_{b} / P_{0}$ pressure drop. In this case the major error in criterion dependencies of thermal model will relate to the value of coefficient at the Re number. If the comparison of experimental and calculated heat flows $q_{z} / q_{c}$, obtained for various pressure drops, gives the same value of variation in considered areas, one can conclude that the $m$ exponent in the used criterion dependence of $\mathrm{Nu}_{i}=A_{i} \mathrm{Re}_{i}{ }^{m}$ kind corresponds to the nature of cooling air flow.

In this case, criterion dependencies of thermal model for the calculation of heat transfer to the cooling air can be defined more precisely by using the $\Delta K_{i}$ correction factor:

$$
\Delta K_{i}=\frac{q_{c i}}{q_{z i}} .
$$

Then the revised value of $A_{c i}$ in the criterion equation is equal to

$$
A_{c i}=\Delta K_{i} \cdot A_{i} .
$$

As various modes of cooling system operation with respect to pressure drops demonstrate essential difference of $q_{z} / q_{c}$, one can assume that the value of $m$ exponent in the criterion equation $m$ at this section of passage differs from that accepted in the thermal model. Usually turns of flow, stagnant zones in flow confluence points, areas of jet, and cyclone cooling can be these sections of passage [23-26].

In this case, the results of blade test in the molten metal thermostat are used for calculation of local heat transfer coefficients and derivation of criterion equation for the purpose of elaboration of thermal model.

\section{Verification Technique Approbation}

The developed technique was applied for verification of thermal model of blade of high-pressure turbine of a fixed gas turbine unit. The blade had an air distribution duct cooling system with ejection of air into the flow range of turbine through the slit in the exit edge and through the hole in 


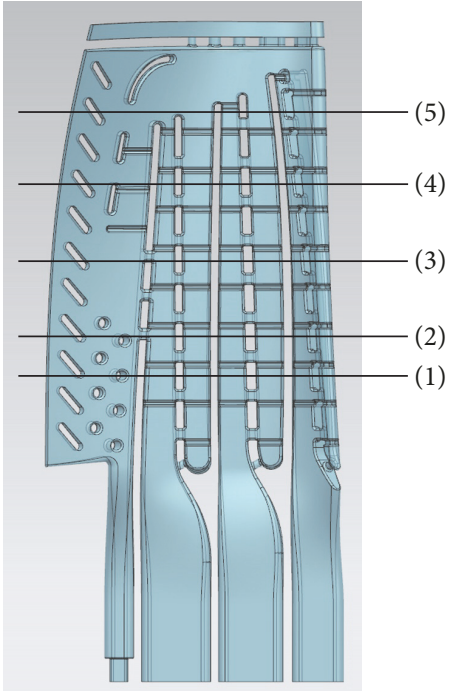

(a) Longitudinal section

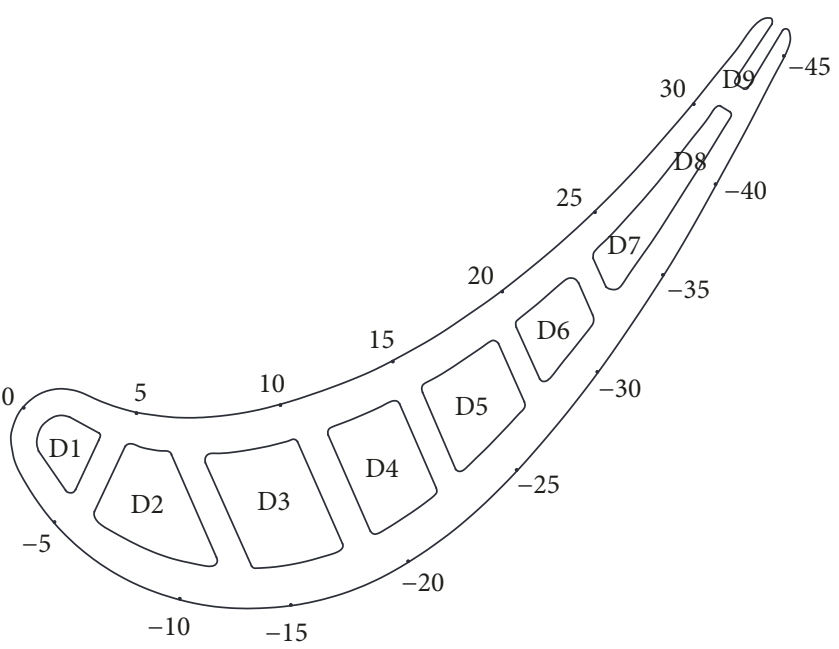

(b) Cross section 3

Figure 5: Blade.

the end wall of blade. Figure 5 demonstrates a longitudinal section of internal space of the blade and cross section 3 in the middle throughout the blade length. A centrifugal flow of cooling air is realised in ducts D1-D6.

Figure 6 demonstrates that the internal channels of blade were modelled as an equivalent hydraulic network. The input node has number 20 and the output node 89 . The pressure difference in the cooling path is modelled by setting pressure in these nodes. The calculation was carried out using the program "Gidra," developed by Baranov Central Aircraft Engine Institute.

The calculations were carried out for pressure differences corresponding to the experimental conditions. The wall temperature of the model was set equal to the crystallization temperature of zinc. The air heating in the channels was determined from the heat balance equation for each channel of the cooling path:

$$
\Delta T_{\mathrm{a} i}^{*}=\frac{\sum q_{i}}{C_{p} \cdot G_{\mathrm{a} i}} .
$$

The cooling air flow through the internal passages of the blade was measured under isothermal conditions: the wall temperature was equal to the air temperature. The difference between experimental and calculated consumption characteristics does not exceed 3\%. Thus, the hydraulic model of the blade is adequate.

The blades were refined for tests: to reduce the thermal inertia the lock was abraded. The collectors for air extraction were made of a tube with a diameter of $20 \mathrm{~mm}$ and soldered with high-temperature solder in a vacuum furnace. The photo of the prepared blade is shown at Figure 7. To measure the temperature of the air at the inlet and outlet in section 3, the thermocouples were installed.

The values of the cooling air temperature, the blade inlet pressure, and the cooling air flow were recorded on the

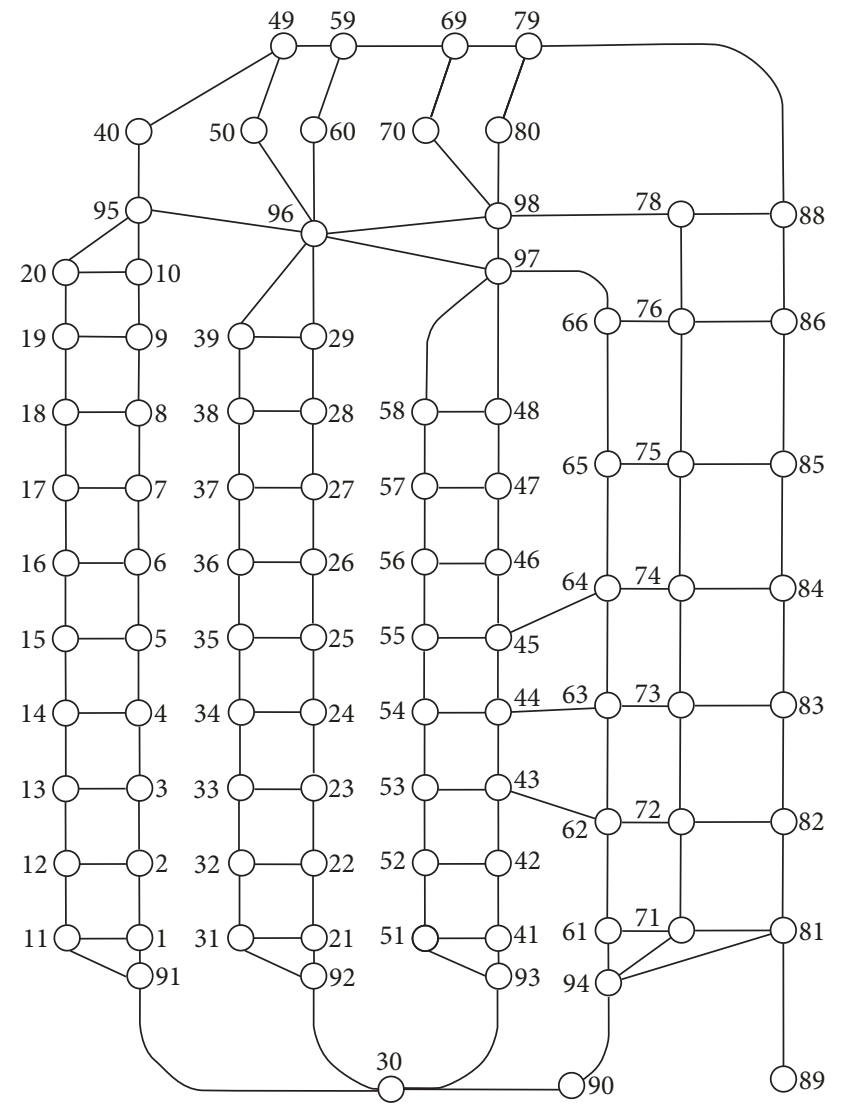

FIgURE 6: An equivalent hydraulic network of the blade cooling channels.

hard disk of the National Instruments industrial computer. Recording resolution was equal to $0.1 \mathrm{~s}$. The accuracy of the temperature measurement was $\pm 1^{\circ}$. The accuracy of the air flow measurement was $\pm 0.1 \mathrm{~g} / \mathrm{s}$. 


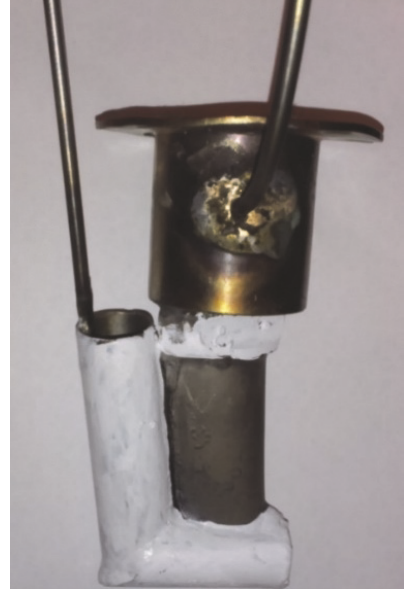

FIGURE 7: The blade model prepared for test.

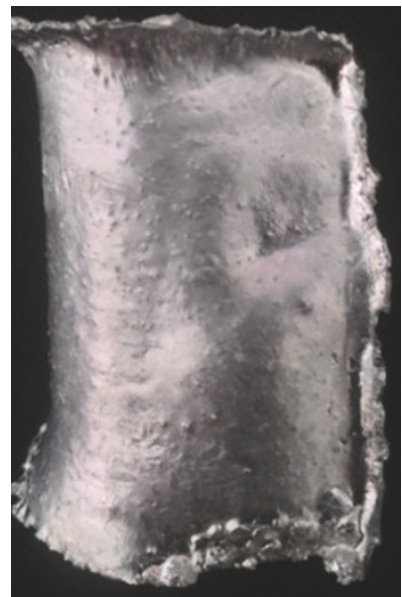

FIGURE 8: Photograph of zinc coat obtained under the pressure drop $P_{b} / P_{0}=1.68$.

A comparison between experimental and calculated values of the air outlet temperatures from the trailing edge showed that the difference does not exceed $9 \%$. This allows us to conclude that the thermal model accurately calculates the total heating of air in the channels. Thus, the thermal model of the blade allows calculating the total air heating in the channels accurately.

The blade was blown in the zinc melt under pressure drops $P_{b} / P_{0}=1.48,1.68,1.78,1.97$, and 2.37. $P_{b}$ represents the cooling system inlet pressure, and $P_{0}$ represents the atmospheric one. For each working mode three experiments were carried out. Each thermogram (zinc crust) obtained during the tests was checked by the heat balance (see (1)).

Figure 8 demonstrates a photograph of zinc coat (from the back side) obtained under the pressure drop $P_{b} / P_{0}=1.68$. The thickness of coat unambiguously characterises the heat exchange intensity.

The qualitative analysis of coat demonstrates zones of duct flow along the blade. At the blade periphery, behind the barrier forming the flow turn into the duct of exit edge, an

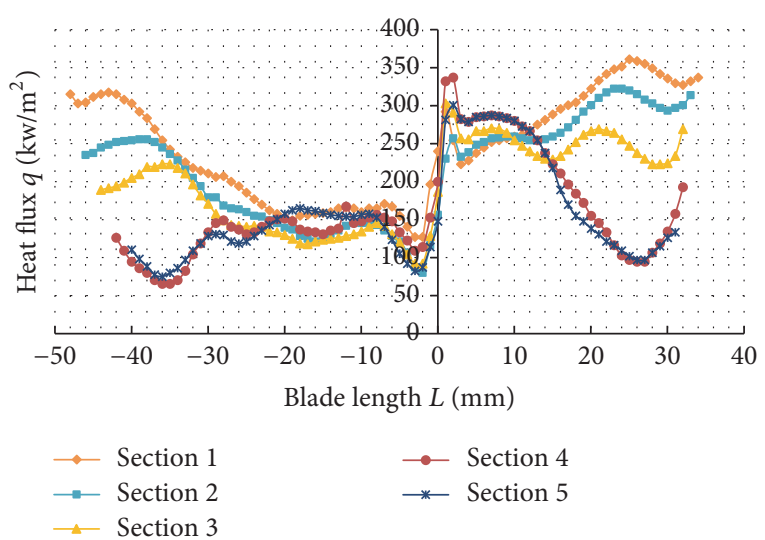

FIGURE 9: Heat flux in sections of blade obtained by averaging over three prototypes, $P_{b} / P_{0}=1.68$.

abrupt decrease of coat thickness was observed. It allows for assumption that there is a stagnant zone behind the barrier which causes the decrease of intensity of heat exchange.

Coats have been cut in calculated sections using the electric erosive method. Images of sections have been enlarged by 20 times and marked with the $1 \mathrm{~mm}$ step along the outer surface. Then the thickness of zinc coat was measured. An absolute error of coat thickness measurement did not exceed $0.01 \mathrm{~mm}$. Then measured values of coat thickness $\delta_{i}$ have been averaged over the experiments. The obtained average value of $\delta_{i \text { av }}$ was used for calculation of heat flux along the outer surface of blade.

Graphs of distribution of heat fluxes along the outer surface in five sections depending on the pressure drop were drawn; a graph for the pressure drop $P_{b} / P_{0}=1.68$ is shown in Figure 9.

Heat flows from the back side are greater by 1.8-2.0 times. At the exit edge from the back side, $q$ is greater by $10-20 \%$. In sections 1, 2, and 3 the decrease of heat flows from the root sections to peripheral ones is observed in radial ducts. It is related to the heating of air along the duct length and the increase of its temperature. In sections 4 and 5 an abrupt decrease of heat flows after section length $L=15 \mathrm{~mm}$ from the pressure side and $L=-26 \mathrm{~mm}$ from the back side is observed.

The local minima of heat flows $\left(q=90-100 \mathrm{~kW} / \mathrm{m}^{2}\right)$ are located from the back side in the point $L=-36 \mathrm{~mm}$ and from the pressure side in $L=26 \mathrm{~mm}$. The heat flow in the local minima points decreases by 2.5-4 times compared to analogous points of sections 1,2, and 3. Two air flows moving in the opposite directions meet in this area of internal space and form a stagnant zone. The stagnant zone can shrink during the rotation due to the action of centrifugal forces [2731].

In order to verify the thermal model of blade, the distribution of heat flux in five sections along the blade length for two pressure drop values of 1.48 and 1.97 was calculated using special software developed for this purpose. The program allows calculating $q_{z i}$ at specified points on the blade outer surface and providing the rapid formulation and solution of medium-sized computational grids (about 1000-1500 grid 


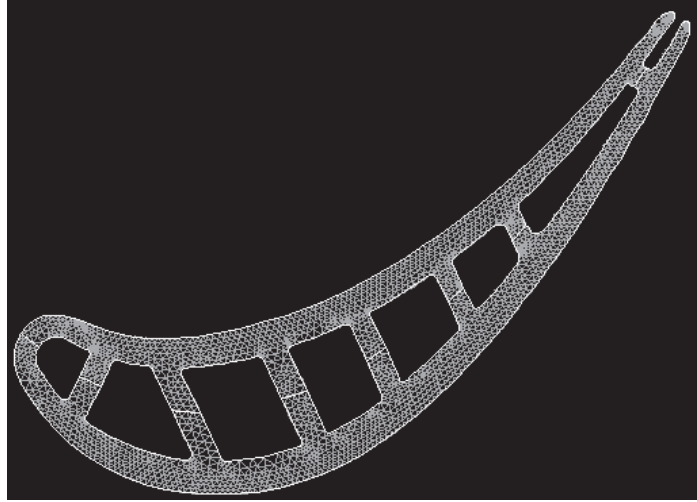

(a) Computational grid

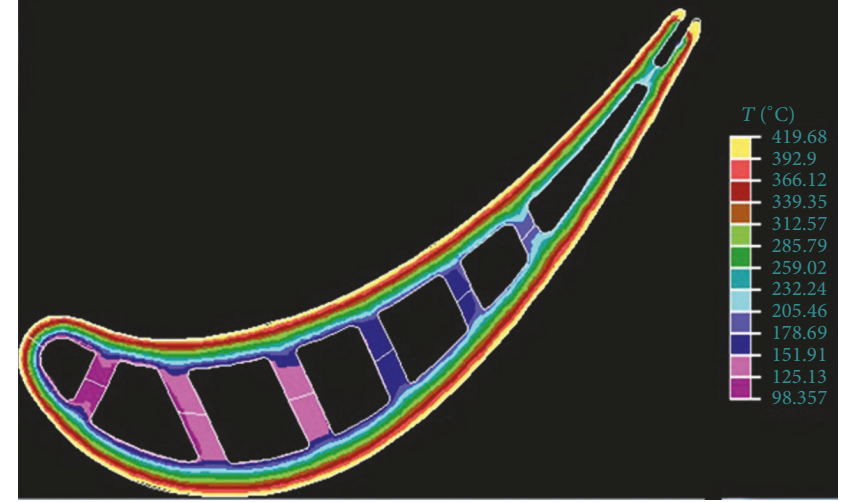

(b) Temperature field for test conditions in the molten metal thermostat, $P_{b} / P_{0}=1.97$

FIGURE 10: Section 3 of the blade.

nodes). It solves two-dimensional steady and unsteady state thermal conduction equations. The following mathematical formulation of the thermal conductivity process is used in program:

(i) plane-parallel steady flow:

$$
\frac{d}{d x}\left(\lambda \cdot \frac{d T}{d x}\right)+\frac{d}{d y}\left(\lambda \cdot \frac{d T}{d y}\right)=Q
$$

(ii) plane-parallel unsteady flow:

$$
\frac{d}{d x}\left(\lambda \cdot \frac{d T}{d x}\right)+\frac{d}{d y}\left(\lambda \cdot \frac{d T}{d y}\right)+R C \cdot \frac{d T}{d \tau}=Q
$$

where $\lambda$ represents thermal conductivity; $T$ represents temperature; $Q$ represents power of the heat source/sink.

As an example, the computational grid for the section 3 is represented at Figure 10(a). The number of nodes was equal to 1400 . The calculated temperature field in section 3 for the test conditions in zinc melt under the pressure drop of 1.97 is demonstrated at Figure 10(b). The obtained calculated values of heat flow $q_{c i}$ have been compared to results of experiments in the molten metal thermostat $q_{z i}$.

Figure 11 demonstrates the distribution of heat flux $q_{z}$ and heat flux $q_{c}$ in middle section 3 of the model for two values of pressure drop equal to 1.48 and 1.97 .

For each point of $i$ on the surface, the permissive variation $\left(q_{z} / q_{c}\right)_{p}$ was determined based on the assumed permissive variation of blade surface temperature during the operation equal to $\pm 10 \mathrm{~K}$. The use of $\left(q_{z} / q_{c}\right)_{p}$ allowed determining zones of discrepancy of thermal model and experimental results. These zones are the leading edge and ducts D5-D8 (the pressure side and the back side).

Comparison of $q_{z} / q_{c}$ parameter obtained under two pressure drops (Figure 11) has revealed that the difference in all sections does not exceed 5\%. It allows concluding that exponents in criterion equations of thermal model accepted as equal to $m=0.8$ describe the specificity of heat exchange in ducts correctly.

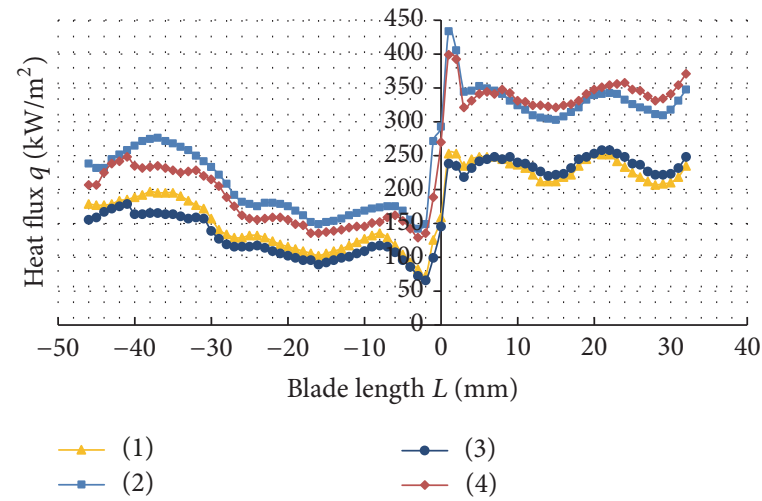

FIGURE 11: Distribution of heat flux along the surface of section 3: (1, 3) $P_{b} / P_{0}=1.48 ;(2,4) P_{b} / P_{0}=1.97 ;(1,2) q_{z} ;(3,4) q_{c}$.

As $q_{z} / q_{c}>\left(q_{z} / q_{c}\right)_{p}$ at particular areas of blade, the elaboration of thermal model using the dependency (11) and (12) was performed according to developed technique.

\section{Conclusions}

(1) An experimental method for thermal model verification of the blade with convective internal cooling based on the comparison of heat fluxes obtained by numerical modelling and experimental investigation in the molten metal thermostat was developed. The error of determination of local heat transfer coefficients using this method does not exceed $8 \%$ for blades with radial channels. An important feature of the method is that the heat load remains unchanged during the experiment and the blade outer surface temperature equals zinc melting point $-692.4 \mathrm{~K}$. This experimental approach allows eliminating an influence of heat transfer on the results accuracy.

(2) The dependencies for estimation of calculation and experimental values of the heat flux influence on relative depth of the blade cooling under operation conditions were obtained. 
(3) The verification of thermal-hydraulic model of highpressure turbine blade with cooling allowing asymmetrical heat removal from pressure and suction sides was carried out using the developed method. The areas of blade requiring more accurate thermal model were identified.

(4) An analysis of heat flux distribution on the outer blade surface allows identifying more intensive cooling on the pressure side due to used heat transfer turbulators. The qualitative analysis of coat allows identifying the location of the area with low heat transfer. It is located in the peripheral blade sections behind the turning rib (sections 4 and 5) and associated with the formation of stagnation zone.

(5) An analysis of heat transfer coefficients confirmed the high level of heat transfer in the leading edge, whose value is comparable with jet impingement heat transfer. The maximum of the heat transfer coefficients is shifted from the critical point of the leading edge to the pressure side. A high intensification of heat transfer in the radial channels was detected and it was 1.5-2 times higher on the pressure side.

\section{Conflicts of Interest}

The authors declare that they have no conflicts of interest.

\section{Acknowledgments}

This study conducted by Moscow Power Engineering Institute has been sponsored financially by the Russian Federation through the Ministry of Education and Science of the Russian Federation under Subsidy Agreement no. 14.577.21.0210 of September 28, 2016, as a part of the Federal Targeted Programme for R\&D in Priority Fields for the Development of Russia’s S\&T Complex for 2014-2020, with Applied Scientific Research Unique Identifier RFMEFI57716X0210.

\section{References}

[1] R. F. Hoeft, J. Janawitz, and R. Keck, Heavy-duty gas turbine operating and maintenance considerations, GE Energy Services, GA, USA, 1993.

[2] J.-C. Han, S. Dutta, and S. Ekkad, Gas turbine heat transfer and cooling technology, CRC Press, Boca Raton, FL, USA, 2nd edition, 2012.

[3] J. Hou, B. J. Wicks, and R. A. Antoniou, "An investigation of fatigue failures of turbine blades in a gas turbine engine by mechanical analysis," Engineering Failure Analysis, vol. 9, no. 2, pp. 201-211, 2002.

[4] B. L. Koff, "Gas turbine technology evolution: A designer's perspective," Journal of Propulsion and Power, vol. 20, no. 4, pp. 577-595, 2004.

[5] D. Chandran and B. Prasad, "Conjugate heat transfer study of combined impingement and showerhead film cooling near NGV leading edge," International Journal of Rotating Machinery, vol. 2015, Article ID 315036, 2015.

[6] M. E. Taslim and J. S. Halabi, "Heat transfer and friction studies in a tilted and rib-roughened trailing-edge cooling cavity with and without the trailing-edge cooling holes," International Journal of Rotating Machinery, vol. 2014, Article ID 710450, 14 pages, 2014.
[7] I. V. Shevchenko, A. N. Rogalev, I. V. Garanin, A. N. Vegera, and V. O. Kindra, "Research and development of asymmetrical heat transfer augmentation method in radial channels of blades for high temperature gas turbines," Journal of Physics: Conference Series, vol. 891, no. 1, Article ID 012142, 2017.

[8] I. V. Shevchenko, I. V. Garanin, A. N. Rogalev, V. O. Kindra, and V. P. Khudyakova, "Study of design and technology factors influencing gas turbine blade cooling," Journal of Physics: Conference Series, vol. 891, no. 1, Article ID 012253, 2017.

[9] D. C. Wilcox, Turbulence modeling for CFD, DCW Industries, Inc, La Canada, Calif, USA, 2nd edition, 1998.

[10] J. E. Bardina, P. G. Huang, and T. Coakley, "Turbulence modeling validation," in Proceedings of the 28th Fluid Dynamics Conference, Snowmass Village, CO, USA.

[11] C. G. Speziale, "Turbulence modeling for time-dependent RANS and VLES: A review," AIAA Journal, vol. 36, no. 2, pp. 173-184, 1998.

[12] M. I. Osipov and A. V. Veretelnik, Modeling of conjugate problem of friction and heat exchange in transpiration cooling of blades of gas turbines, vol. 1 of Mechanical Engineering, Herald of the Bauman Moscow State Technical University, 2007.

[13] C. Lane, The Development of a 2D ultrasonic array inspection for single crystal turbine blades, Springer International Publishing, Cham, Switzerland, 2014.

[14] G. J. S. Higginbotham, "Method of making gas turbine engine blades," Patent US 4417381 A, 1981.

[15] P. W. Schilke, Advanced Gas Turbine Materials And Coatings, E Energy, Schenectady, NY, USA, 2004.

[16] D. W. Richerson, Modern ceramic engineering: properties, processing, and use in design, CRC Press, Boca Raton, FL, USA, 3rd edition, 2006.

[17] H. Harada, "High temperature materials for gas turbines: the present and future," in Proceedings of the International Gas Turbine Congress, Tokyo, Japan, 2003.

[18] K. Mohaghegh, M. H. Sadeghi, and A. Abdullah, "Reverse engineering of turbine blades based on design intent," The International Journal of Advanced Manufacturing Technology, vol. 32, no. 9-10, pp. 1009-1020, 2007.

[19] L.-C. Chen and G. C. I. Lin, "Reverse engineering in the design of turbine blades - a case study in applying the MAMDP," Robotics and Computer-Integrated Manufacturing, vol. 16, no. 2, pp. 161-167, 2000.

[20] J. Gao, X. Chen, D. Zheng, O. Yilmaz, and N. Gindy, "Adaptive restoration of complex geometry parts through reverse engineering application," Advances in Engineering Software, vol. 37, no. 9, pp. 592-600, 2006.

[21] I. V. Shevchenko, A. N. Rogalev, M. I. Shevchenko, and A. N. Vegera, "Method of calorimetric measurements in molten metal thermostat and its application for developing blade cooling system of gas turbines," International Journal of Applied Engineering Research, vol. 12, no. 10, pp. 2382-2386, 2017.

[22] I. V. Shevchenko and Y. W. Kim, "Calorimetric heat transfer measurement in zinc bath and its application to blade internal cooling system development," in Proceedings of the in Proceedings of the 1997 International Mechanical Engineering Congress Exposition, Dallas, TX, USA, November 1997.

[23] A. Khalatov, N. Syred, P. Bowen, R. AI-Ajmi, A. Kozlov, and A. Schukin, "Innovative cyclone cooling scheme for gas turbine blade: Thermal-hydraulic performance evaluation," in Proceedings of the ASME Turbo Expo 2000: Power for Land, Sea, and Air, GT 2000, Germany, May 2000. 
[24] A. A. Khalatov, N. Syred, P. J. Bowen, and R. Al-Ajmi, "Quasi two-dimensional cyclone-jet cooling configuration: Evaluation of heat transfer and pressure losses," in Proceedings of the ASME Turbo Expo 2001: Power for Land, Sea, and Air (GT'01), New Orleans, LA, USA, 2001.

[25] N. Winter and H. Schiffer, "Effect of rotation on the cyclone cooling method mass transfer measurements," in Proceedings of International Symposium on Heat Transfer in Gas Turbine Systems, pp. 1-17, Antalya, Turkey, 2009.

[26] A. A. Khalatov, N. Syred, P. J. Bowen, and R. Al-Ajmi, "Enhanced cyclone cooling technique for high performance gas turbine blades," in Proceedings of the 12-th International Heat Transfer Conference, Grenoble, France, 2002.

[27] J. W. Wagner, B. V. Johnson, and F. C. Kopper, "Heat transfer in rotating serpentine passages with smooth walls," Journal of Turbomachinery, vol. 113, no. 3, pp. 321-330, 1991.

[28] W. D. Morris and T. Ayhan, "Observations on the influence of rotation on heat transfer in the coolant channels of gas turbine rotor blades," Proceedings of the Institution of Mechanical Engineers, vol. 193, pp. 303-311, 1979.

[29] B. V. Johnson, J. H. Wagner, G. D. Steuber, and F. C. Yeh, "Heat transfer in rotating serpentine passages with trips skewed to the flow," in Proceedings of the ASME 1992 International Gas Turbine and Aeroengine Congress and Exposition, GT 1992, Germany, June 1992.

[30] M. E. Taslim, A. Rahman, and S. D. Spring, "An experimental investigation of heat transfer coefficients in a spanwise rotating channel with two opposite rib-roughened walls," in Proceedings of the ASME International Gas Turbine and Aeroengine Congress and Exposition (GT'89), Toronto, Canada, 1989.

[31] T. Lei, Y. Zhiyi, X. Yun, L. Yabin, and C. Shuliang, "Role of blade rotational angle on energy performance and pressure fluctuation of a mixed-flow pump," Proceedings of the Institution of Mechanical Engineers, Part A: Journal of Power and Energy, vol. 231, no. 3, pp. 227-238, 2017. 


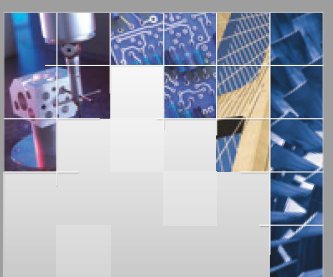

\section{Enfincering}
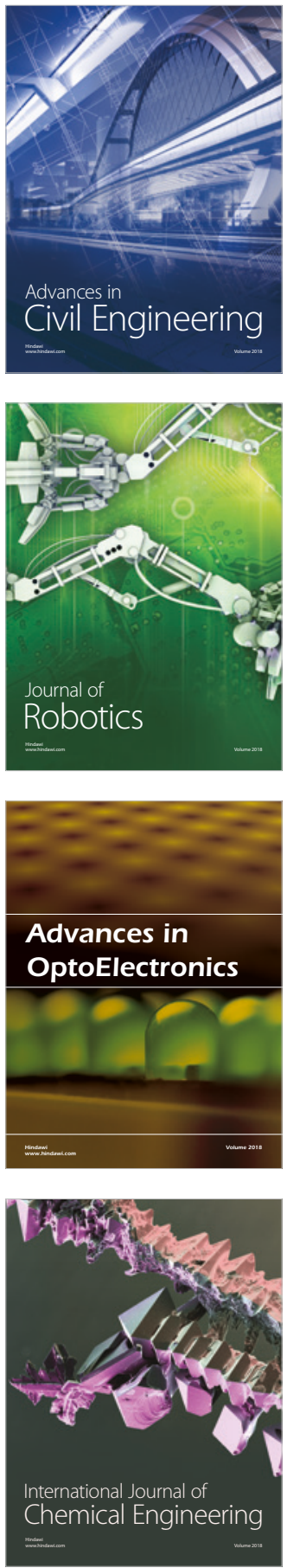

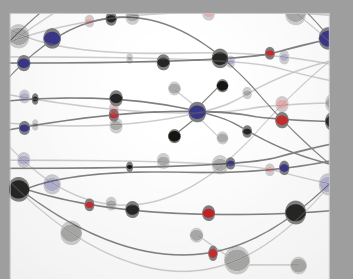

\section{Rotating \\ Machinery}

The Scientific World Journal

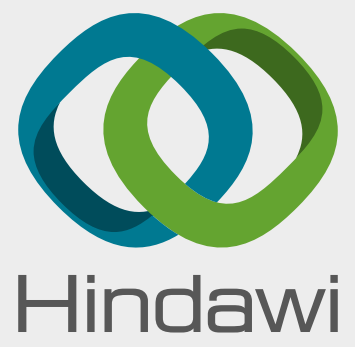

Submit your manuscripts at

www.hindawi.com
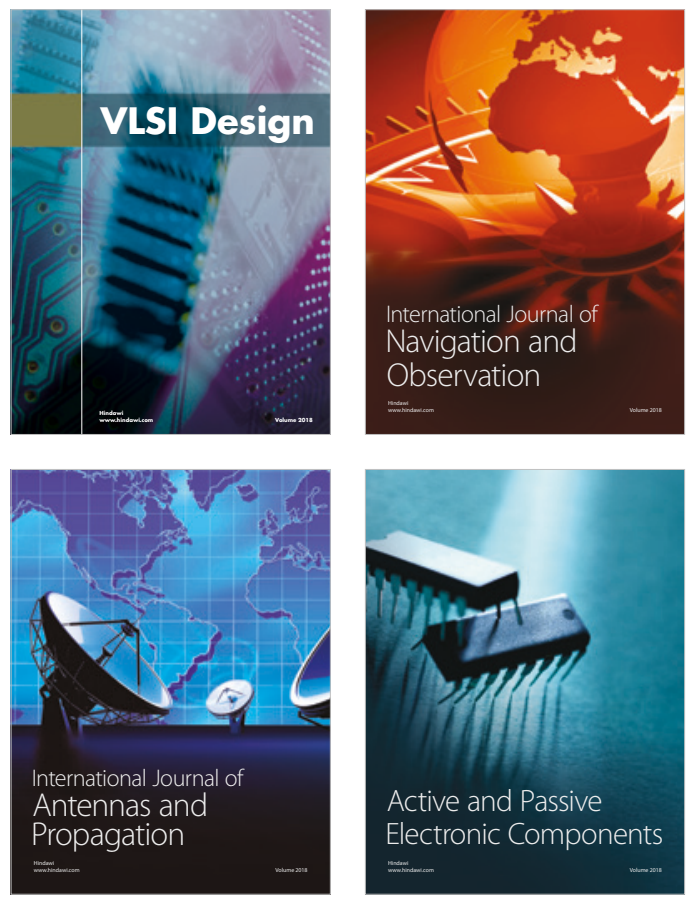
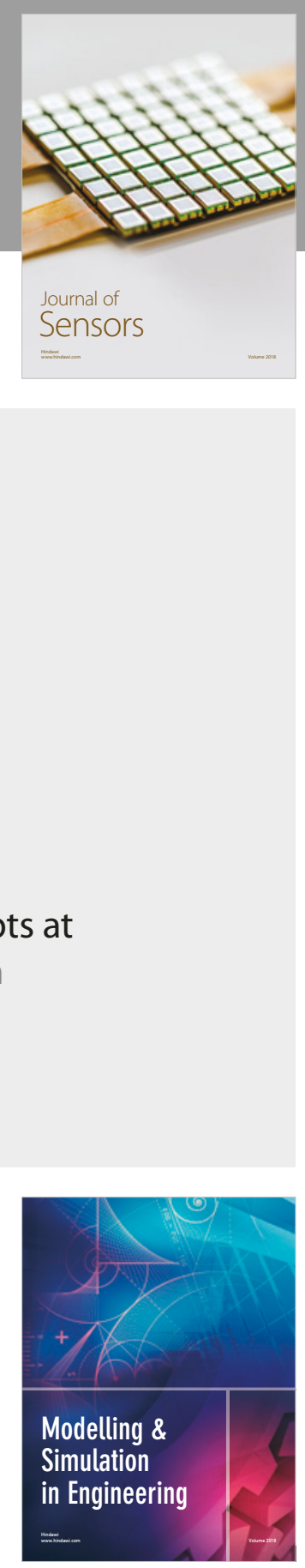

\section{Advances \\ Multimedia}
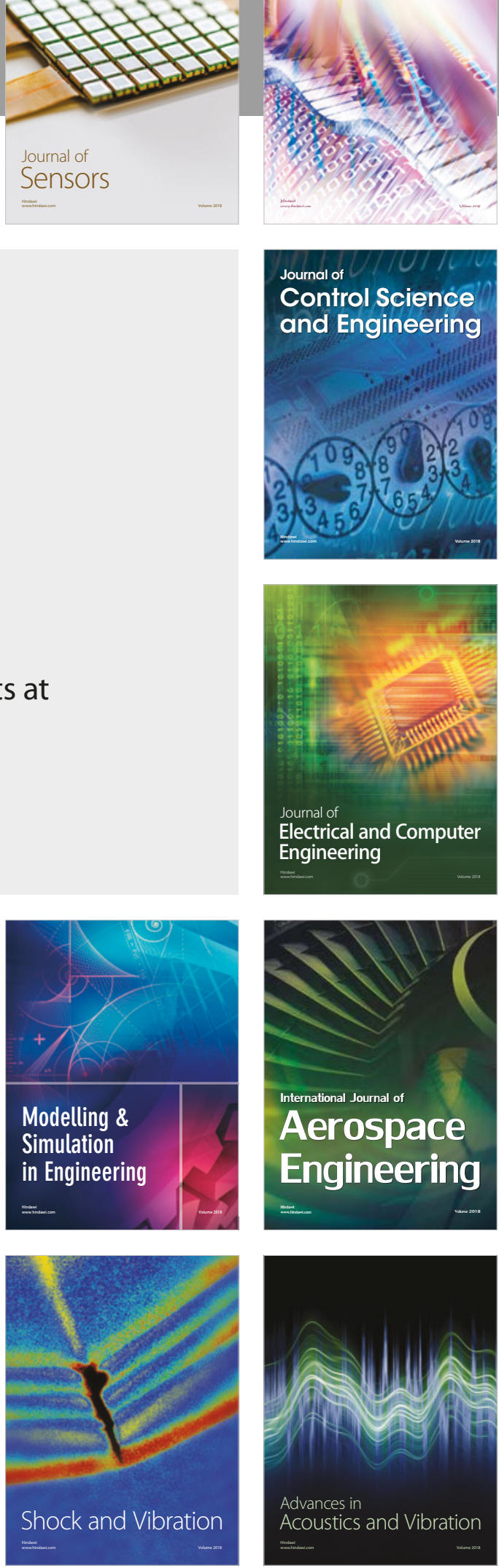